\title{
GRÜNWEDEL Albert, Briefe und Dokumente
}

édité par Hartmut Walravens, Wiesbaden, Harrassowitz Verlag, 2001, 206 pages

\section{Nicola Schneider}

\section{(C) OpenEdition}

\section{Journals}

\section{Édition électronique}

URL : https://journals.openedition.org/emscat/483

DOI : 10.4000/emscat.483

ISSN : 2101-0013

Éditeur

Centre d'Etudes Mongoles \& Sibériennes / École Pratique des Hautes Études

Édition imprimée

Date de publication : 1 décembre 2004

Pagination : 236-237

ISBN : 2-9518888-2-1

ISSN : 0766-5075

Référence électronique

Nicola Schneider, « GRüNwEDEL Albert, Briefe und Dokumente », Études mongoles et sibériennes, centrasiatiques et tibétaines [En ligne], 35 | 2004, mis en ligne le 22 février 2009, consulté le 13 juillet 2021. URL : http://journals.openedition.org/emscat/483 ; DOI : https://doi.org/10.4000/emscat.483

Ce document a été généré automatiquement le 13 juillet 2021.

(ㄷ) Tous droits réservés 


\section{GRÜNWEDEL Albert, Briefe und Dokumente}

édité par Hartmut Walravens, Wiesbaden, Harrassowitz Verlag, 2001, 206 pages

\section{Nicola Schneider}

\section{RÉFÉRENCE}

GRÜNWEDEL Albert, Briefe und Dokumente, édité par Hartmut Walravens (Wiesbaden, Harrassowitz Verlag, 2001) 206 p.

1 Albert Grünwedel (1856-1935) était renommé comme indianiste, tibétologue, archéologue, mais aussi comme administrateur du musée d'Ethnologie de Berlin. Il s'intéressa principalement aux textes : après avoir rédigé son doctorat (1883) sur la grammaire pali, il se pencha sur la littérature tibétaine, puis élabora un glossaire de la langue lepcha. Bien qu'ayant travaillé toute sa vie dans un musée d'Ethnologie, il resta sceptique envers les méthodes et les idées de ces ethnologues qui occupaient, selon lui, une place bien trop importante. En revanche, il participa activement à la création de l'actuel musée d'Art indien de Berlin. L'une de ses contributions scientifiques majeures fut la direction de la première, puis de la troisième expédition à Tourfan (sur la Route de la Soie, dans l'actuelle région autonome ouïgoure du Xinjiang ou Turkestan oriental). À la suite des découvertes faites lors de ces expéditions, Grünwedel rédigea plusieurs rapports archéologiques, suivis de publications sur la culture et l'art en Asie centrale. Ses voyages et les résultats qui en découlèrent doivent beaucoup à sa connaissance de la langue russe et à ses bons rapports avec ses collègues russes. La publication d'un catalogue des collections « lamaïques » du prince Oukhtomsky en est un exemple.

2 La collection de lettres et de documents écrits par Grünwedel - objet du livre édité par Hartmut Walravens - permet au lecteur de suivre la démarche de l'auteur et les échanges qu'il entretint avec les scientifiques de son temps. La moitié des lettres sont 
adressées à Ernst Kuhn (1846-1920), indianiste et spécialiste de la culture iranienne, qui fut son professeur. Grünwedel avait gardé un contact étroit avec son maître à qui il transmettait régulièrement les résultats de ses recherches. Kuhn, de son côté, soutint à diverses reprises ses projets, et notamment ses expéditions à Tourfan. Quelques missives envoyées lors de ces voyages retracent l'état des temples et des monastères des vallées de Kharakhodja et de Ouchak, ainsi que ceux de Koutcha, Chortchouk, Ouroumtchi, Khami, Assa Chari et Mourotuk, et donnent une idée de la diversité des objets - souvent en mauvais état - et des textes (écrits en tibétain, sanscrit, ouïgour, brahmi, etc.) trouvés sur place.

3 Le livre reproduit également sa correspondance occasionnelle avec d'autres personnalités, entre autres Ernst Boerschmann (1873-1949, architecte et sinologue), Felix von Luschan (1854-1924, ethnologue), Richard Andree (1835-1912, géographe), Carl Bezold (1859-1922, orientaliste), ainsi qu'avec la bibliothèque universitaire de Göttingen.

4 Dans ces lettres, on trouve essentiellement des renseignements concernant le travail de Grünwedel : d'une part, constitution de collections pour les musées (lettres à F. von Luschan et à ses collègues de Göttingen) et, d'autre part, échange, traduction et discussion de textes provenant d'Asie centrale (lettres à E. Boerschmann).

5 La dernière grande œuvre de Grünwedel fut une étude du manuscrit, jusqu'alors non publié, du kâlacakratantra. Deux lettres de recommandations et plusieurs courriers témoignant des difficultés rencontrées pour parvenir à faire publier ce travail sont joints à la fin du livre. De même, le lecteur trouvera un rapport dans lequel Grünwedel se défend contre les reproches de plagiat émis par son collègue F.W.K. Müller. Cette dispute entre érudits concernant la primauté de la découverte des Manichéens est également un thème récurrent dans toute la correspondance.

6 L'éditeur a inclus une liste des publications de Grünwedel et des éléments de sa biographie. Un index détaillé des noms permet d'identifier toutes les personnes citées dans les lettres. L'ouvrage s'adresse aux étudiants et aux chercheurs travaillant sur l'Asie centrale, et aussi aux personnes qui s'intéressent à l'histoire des collections des musées berlinois précités. 